\title{
Effective Countermeasures to Improve Passenger Manners
}

\begin{abstract}
Kana YAMAUCHI
Assistant Senior Researcher,

Hiroaki SUZUKI Ph. D.

Ergonomics Laboratory, Human Science Division

\author{
Kyosuke NAKATANI \\ East Japan Railway Company
}

\author{
Takeshi NAKAGAWA \\ East Japan Railway Company
}

Railway companies have adopted various measures to minimize annoying passenger behavior. Questionnaire and monitor surveys conducted on railway station users in core cities confirmed that the degree of awareness is high in the case of "soft" measures such as making announcements or putting up posters in trains or at stations. Depending on the type of annoying behavior and passenger attributes, there are differences in what passengers expect from the measures taken by railway companies. For some ill-mannered passengers, posters including data are more effective than conventional illustrations.
\end{abstract}

Senior Researcher, Laboratory Head,

Keywords: ill-mannered passengers, annoying behavior, countermeasures proposed by railway companies

\section{Introduction}

At train stations or on trains, passengers are often disturbed by the intentional or unintentional bad behavior of other people. At first glance, it often seems that such annoying behavior stems from a general decline in morals and manners. However, a number of critical factors must be considered in a scientific analysis of such behavior ${ }^{1)}$. These range from the high crime rate to the emphasis that is placed on appearance and hygiene, discrepancies in individual values and opinions, as well as the type and degree of disturbance, and the offense or damage caused or harm inflicted. In this study, conducted with a railway company's cooperation, the following points were identified as being key factors in evaluating effective measures against annoying behavior.

(1) Qualitative and quantitative analyses of disturbance and offense or damage caused or harm inflicted

(2) Attitudes and manners that can be adopted as countermeasures

(3) Concrete and effective measures that will reflect railway company attitudes.

Particular attention was drawn to points (2) and (3). It is important to note that (3) is dependent on (2) and has practical importance for most railway companies. Firstly, a simple model for classifying factors related to point (3) was proposed. Secondly, utilizing this classification, results were reported from an investigation into the awareness and demands of passengers regarding what steps railway companies are taking or should take to minimize annoying behavior.

\section{Countermeasure Classification}

\subsection{Examination of main factors}

The following factors were summarized by analyzing the feelings of discomfort, anxiety or annoyance provoked by the behavior of others on trains or at stations. (1) Hazards

Hazards are objects or situations that have the latent potential to cause offense ${ }^{2}$. For the purpose of this report, hazards are defined as behavior, people, or things (e.g. cigarette smoke) that another person may find annoying or unpleasant.

(2) Individual factors

Individual attribute factors are the particular characteristics of the aggrieved person. These include, "demographic factors" such as gender, age, social status; the "knowledge, recollection, experience" of having taken offense before and norm awareness acknowledgement; and "characteristics and values" such as optimism, conservatism and the degree of norm awareness.

(3) Physical environment factors

Physical environment factors are derived from the surrounding environment and include the numbers of people, the function and efficiency of the machinery or equipment, the amount of graffiti and garbage, and the like.

(4) Social environment factors

Social environmental factors are derived from the surrounding social structures and functions that regulate behavior, such as the presence of others, groups, customs and institutions.

\subsection{Types of countermeasures}

This study focused on hazards and environmental factors that annoy passengers, as well as on the countermeasures proposed by railway companies. Attention was drawn to three factors other than the individual characteristics of the aggrieved person. Table 1 summarized the countermeasures proposed by railway companies for dealing with these primary factors. Technical (or 'hard') 
Table 1 Countermeasure classification

\begin{tabular}{|l|l|}
\hline \multicolumn{1}{|c|}{ Type } & \multicolumn{1}{c|}{ Countermeasure method } \\
\hline $\begin{array}{l}\text { Physical } \\
\text { environment }\end{array}$ & Technical (or 'hard') policies \\
\hline $\begin{array}{l}\text { Social } \\
\text { environment }\end{array}$ & $\begin{array}{l}\text { Laws } \\
\text { Regulations decided by railway companies }\end{array}$ \\
\hline Hazards & $\begin{array}{l}\text { Education, instruction, self-discipline, and other infor- } \\
\text { mation ('soft') methods } \\
\text { Patrols, surveillance }\end{array}$ \\
\hline
\end{tabular}

policies can be used to handle problems derived from the physical environment and include such methods as using technology to prevent the use of cellular phones. Procedures for handling problems arising from the social environment include laws and regulations decided by railway companies, such as the establishment of designated smoking and no-smoking areas. Hazards may be dealt with through public relations, self-discipline, education, instruction, development, and other information ("soft") methods, as well as patrols, surveillance, etc. It is expected that the social environment will change as a result of carrying out hazard intervention (e.g. a coercive atmosphere is expected to result from patrolling inside trains).

The secondary effects may be caused by the execution of various countermeasures in table 1. Such effects were not discussed here.

\section{Investigation of countermeasure awareness among passengers}

Two investigations were carried out to examine current countermeasure awareness among passengers and efforts on the part of railway companies to induce the improvement of passenger manners.

\subsection{Methods}

(1) Study 1

Study 1 was conducted over two weekdays in January 2003. Researchers distributed a total of 2200 questionnaires at a train station, which were returned by post. Participants were the users of four train stations within a 50-kilometer radius of Tokyo.

(2) Study 2

Study 2 was conducted over two days (a Friday and Saturday) in October 2003. Because the return-mail questionnaires used in Study 1 did not prove ideal for gather- ing detailed responses, participants were selected from among the approximately 800 people who returned the first questionnaire and expressed a desire to participate in a future study. Invitations for participating in the second investigation were sent to 90 people, evenly distributed according to age and gender. Investigators explained the questionnaire to the participants using audio-visual equipment, and the participants supplied information with respect to the questionnaire.

\subsection{Content of investigation}

\section{(1) Study 1}

Study 1 investigated awareness regarding good manners, passenger behavior, countermeasures aimed at improving passenger manners, the value of advertising and individual attributes. This paper focused on the following three items derived from the investigation of publicservice advertising conducted by railway companies:

1 . The degree of passenger recognition of current countermeasures

2. Requests concerning countermeasures for dealing with annoying behavior

3. Awareness of effective countermeasures aimed at improving passenger manners

(2) Study 2

Based on the Study 1 findings, Study 2 examined the options for advertising strategies aimed at improving passenger manners. In addition, it presented several possible new trial strategies and evaluated their effectiveness. There were two principal targets for the investigation:

1. Evaluation of new measures for increasing user awareness.

2. Comparison of posters showing up-to-date data with traditional posters making full use of illustrations.

\subsection{Participants}

\section{(1) Study 1}

In Study 1, 882 questionnaires were returned from four train stations. The participants' attributes were shown in Table 2. Although the ratio of the number of women under twenty was relatively high, the ratios for other categories were fairly evenly balanced. The majority of respondents were very frequent train users (more than 3-4 times per week, 73.0\%), moderately frequent train users ( several times per month, 24.4\%) and infrequent train users ( several times per year, $2.6 \%$ ).

(2) Study 2

A total of 81 people participated over the two days of Study 2. The attributes of the participants were shown

Table 2 Attributes of participants (\%) to Study 1

\begin{tabular}{lccccccccc}
\hline & & $\begin{array}{c}\text { Under 20 } \\
(\mathrm{n}=255)\end{array}$ & $\begin{array}{c}20-29 \\
(\mathrm{n}=91)\end{array}$ & $\begin{array}{c}30-39 \\
(\mathrm{n}=114)\end{array}$ & $\begin{array}{c}40-49 \\
(\mathrm{n}=119)\end{array}$ & $\begin{array}{c}50-59 \\
(\mathrm{n}=153)\end{array}$ & $\begin{array}{c}\text { Over 60 } \\
(\mathrm{n}=147)\end{array}$ & $\begin{array}{c}\text { Unknown } \\
(\mathrm{n}=3)\end{array}$ & $\begin{array}{c}\text { Total } \\
(\mathrm{n}=882)\end{array}$ \\
\hline Male & $(\mathrm{n}=394)$ & 8.4 & 2.8 & 5.6 & 7.6 & 9.6 & 10.5 & 0.1 & 44.7 \\
Female & $(\mathrm{n}=488)$ & 20.5 & 7.5 & 7.4 & 5.9 & 7.7 & 6.1 & 0.2 & 55.3 \\
Total & $(\mathrm{n}=882)$ & 28.9 & 10.3 & 12.9 & 13.5 & 17.3 & 16.7 & 0.3 & 100.0 \\
\hline
\end{tabular}

Note: Numerical values in the table indicate percentage of total. 
Table 3 Attributes of participants (\%) in Study 2

\begin{tabular}{lcccccccc}
\hline & & $\begin{array}{c}\text { Under 20 } \\
(\mathrm{n}=9)\end{array}$ & $\begin{array}{c}20-29 \\
(\mathrm{n}=8)\end{array}$ & $\begin{array}{c}30-39 \\
(\mathrm{n}=8)\end{array}$ & $\begin{array}{c}40-49 \\
(\mathrm{n}=14)\end{array}$ & $\begin{array}{c}50-59 \\
(\mathrm{n}=19)\end{array}$ & $\begin{array}{c}\text { Over 60 } \\
(\mathrm{n}=23)\end{array}$ & $\begin{array}{c}\text { Total } \\
(\mathrm{n}=81)\end{array}$ \\
\hline Male & $(\mathrm{n}=42)$ & 5.0 & 3.8 & 2.5 & 10.0 & 8.8 & 22.5 & 52.5 \\
Female & $(\mathrm{n}=39)$ & 6.3 & 6.3 & 7.5 & 7.5 & 15.0 & 6.3 & 47.5 \\
Total & $(\mathrm{n}=80)$ & 14.0 & 10.9 & 12.5 & 21.9 & 29.6 & 35.9 & 100.0 \\
\hline
\end{tabular}

Note: Numerical values in the table indicate percentage of total.

in Table 3. The majority of the participants were very frequent train users $(79.1 \%)$, along with moderately frequent train users (19.7\%), and infrequent train users $(1.2 \%)$.

It should be noted that the total responses for each question are not consistent because blank and wrongly entered responses were eliminated from the analysis.

\section{Results and Discussion}

The results from Study 1 were discussed in Sections 4.1-4.3, those from Study 2 in Sections 4.4 and 4.5.

\subsection{Countermeasure awareness}

This study examined user how the passengers recognize the railway company staff's efforts to induce the improvement of passenger manners. Most passengers were aware of these efforts, with $87.8 \%$ responding, "I know about them". In addition, those respondents who answered in the affirmative were asked to provide as many details as possible concerning how they obtained the information. As can be seen in Fig. 1, the higher the frequency of contact, the stronger the impact. This study also investigated

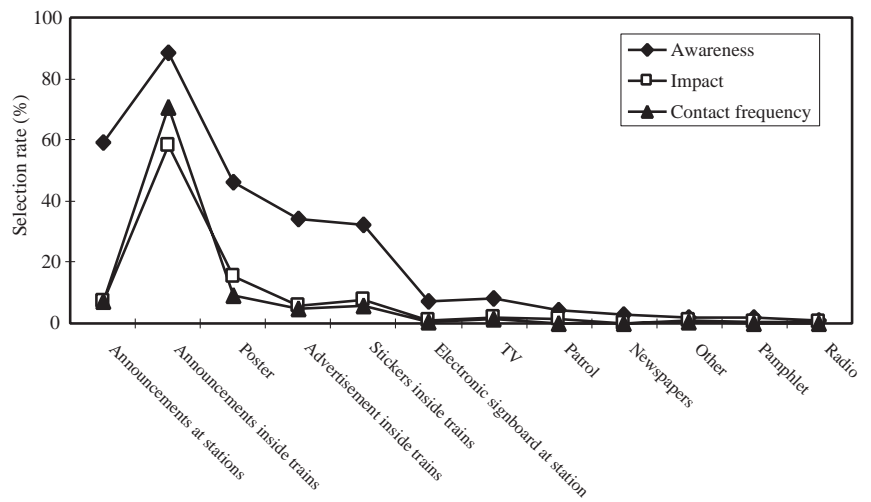

Fig. 1 Media awareness, impact and contact frequency

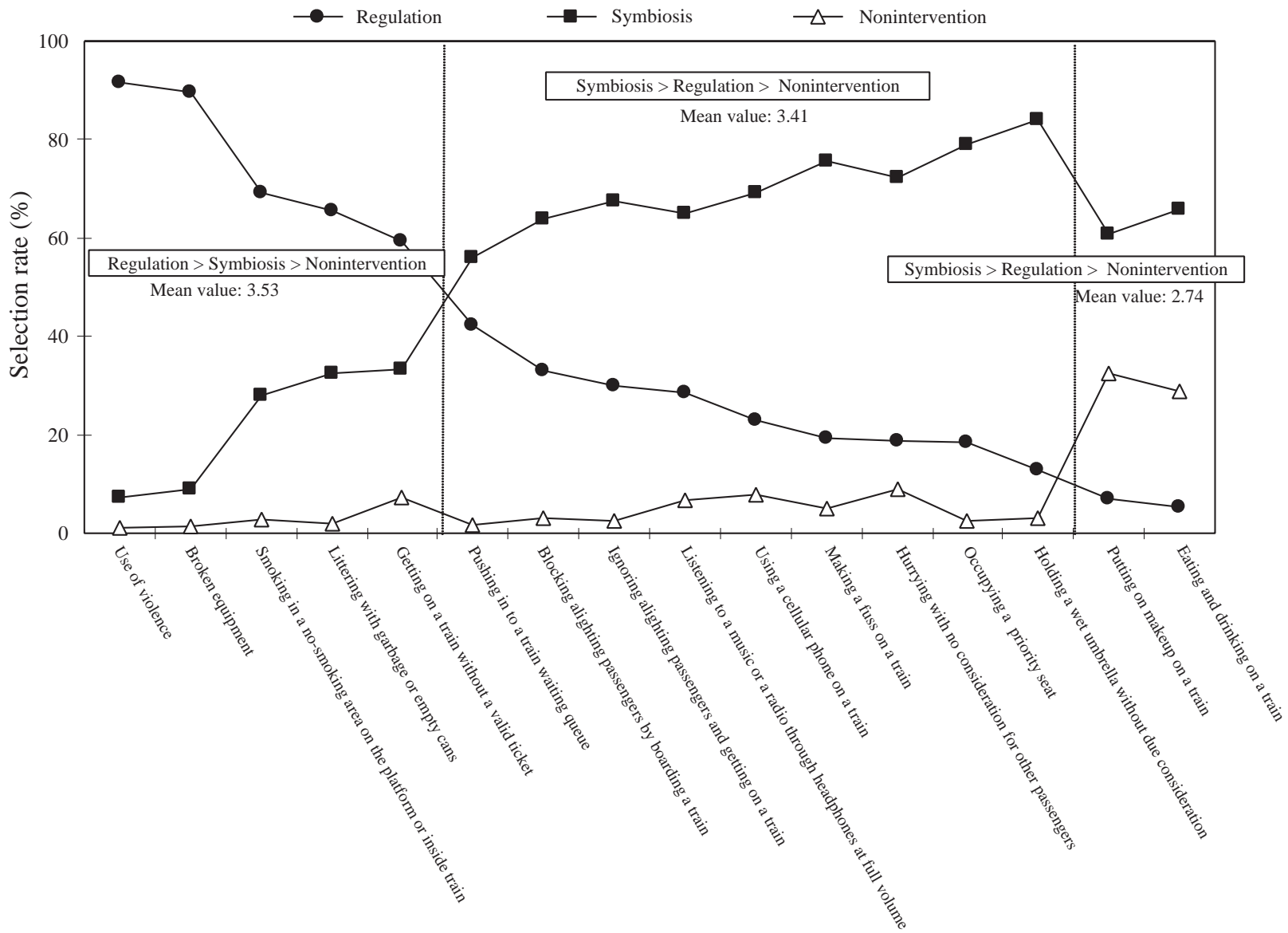

Fig. 2 Patterns for selecting coping strategies and degree of discomfort mean values 
the current standards of public service announcements and posters. This revealed that broadcasts inside trains were very effective for disseminating information.

\subsection{Railway company policies and methods}

This study also inquired about the attitudes and methods passengers expect railway companies to adopt when the company has to cope with individual instances of annoying behavior. Respondents' replies were classified into three categories with respect to such strategies: "regulation", or using stricter rules and regulations, prohibiting people who engage in self-centered behavior, and other such rigid attitudes; "symbiosis", or increasing awareness at an individual level rather than applying rules and regulations; and "nonintervention", or belief that even minimal intervention is not necessary. At the same time, respondents were asked to rate the degree of unpleasantness of each type of behavior on a four-point scale ( $4=$ most unpleasant). Fig. 2 indicated the rate at which each coping strategy was chosen.

Three patterns in choosing coping strategies were observed ("regulation > symbiosis > nonintervention"; "symbiosis > regulation > nonintervention"; "symbiosis $>$ nonintervention $>$ regulation"). The mean value of the degree of discomfort for each of the three annoying behavior patterns was indicated in the figure. For the "regulation > symbiosis > nonintervention" pattern, behavior accompanied by the possibility of injury, such as behavior with a high degree of criminality, or that related to beautification and hygiene, were common. The mean annoyance value was 3.53 , the highest of the three patterns. For the "symbiosis > regulation > nonintervention" pattern, behavior related to self-control, such as those requested by posters and announcements inside train, were common. The mean value of annoyance of 3.41 was lower than behavior related to crime and hygiene. Only two behaviors were apparent in the "symbiosis > nonintervention > regulation") pattern: eating, and putting on makeup when on the train. The degree of discomfort had the lowest mean value of 2.74. Furthermore, the rate of selecting nonintervention was higher than for the other strategies.

\subsection{Perception of measures to improve passenger manners}

The study also investigated the methods that passengers desired as concrete practical policies for a symbiotic coping strategy. Respondents were requested to freely describe their ideas regarding ways to improve passenger manners. Based on the classifications in Table 1, the answers were summarized in Table 4. From the appeal point of view, "hazard intervention" from Table 1 was chosen most frequently ( $84.8 \%)$. On the whole, "instruction and education" were the methods that users found to be

Table 4 Types of countermeasure and rate requested by passengers

\begin{tabular}{|c|c|c|c|c|c|c|c|c|c|}
\hline \multirow[b]{2}{*}{ Category } & \multirow{2}{*}{ Total } & \multicolumn{2}{|c|}{ Gender } & \multicolumn{6}{|c|}{ Age } \\
\hline & & Male & Female & $10-19$ & $20-29$ & $30-39$ & $40-49$ & $50-59$ & Over 60 \\
\hline 1. Hazaed intervention & 84.8 & 95.6 & 84.7 & 87.3 & 82.5 & 86.5 & 75.7 & 84.3 & 88.4 \\
\hline Instruction and education ${ }^{(* *)}$ & 64.8 & 64.3 & 64.6 & 58.7 & 65.0 & 64.9 & 59.2 & 68.7 & 72.5 \\
\hline - Advertisements using media & 60.1 & 54.0 & 67.9 & 70.2 & 69.2 & 57.1 & 45.9 & 65.3 & 49.0 \\
\hline$\cdot$ Manner education & 21.7 & 24.1 & 19.8 & 11.8 & 19.3 & 22.4 & 32.9 & 22.9 & 26.0 \\
\hline - Cooperation with other organizations & 9.0 & 12.2 & 3.4 & 6.3 & 3.8 & 11.1 & 13.1 & 8.9 & 11.0 \\
\hline - Self-discipline & 6.1 & 6.9 & 5.5 & 7.2 & 5.8 & 7.9 & 4.9 & 2.9 & 8.0 \\
\hline - Publishing the results of research & 3.1 & 2.8 & 3.4 & 4.5 & 1.9 & 1.5 & 3.2 & 0.0 & 6.0 \\
\hline Reinforcement of patrol and surveillance $e^{(* *)}$ & 20.0 & 31.3 & 20.1 & 28.6 & 17.5 & 21.6 & 16.5 & 15.6 & 15.9 \\
\hline · Patrol & 86.0 & 90.9 & 81.1 & 87.0 & 78.6 & 85.7 & 70.6 & 91.3 & 95.4 \\
\hline - Surveillance & 14.0 & 9.1 & 18.9 & 13.0 & 21.4 & 14.3 & 29.4 & 8.7 & 4.6 \\
\hline 2. Intervention into social environment & 15.2 & 15.7 & 15.2 & 12.7 & 17.4 & 13.4 & 24.3 & 15.7 & 11.6 \\
\hline Establishing rules and penalties ${ }^{(* *)}$ & 11.5 & 11.0 & 12.5 & 10.6 & 16.2 & 9.3 & 19.4 & 10.9 & 6.5 \\
\hline - Limitation of area ${ }^{(* * *)}$ & 48.2 & 48.8 & 47.9 & 35.0 & 15.3 & 44.4 & 65.0 & 56.3 & 77.8 \\
\hline - Tightening controls after deciding a rule & 25.3 & 22.0 & 28.2 & 30.0 & 38.4 & 22.2 & 15.0 & 31.3 & 11.1 \\
\hline - Establishing a penalty system & 21.8 & 22.0 & 21.7 & 20.0 & 38.4 & 33.3 & 20.0 & 12.5 & 11.1 \\
\hline - Other (Paying rewards to those who report offense, etc.) & 4.6 & 7.3 & 2.1 & 15.0 & 7.7 & 0.0 & 0.0 & 0.0 & 0.0 \\
\hline Creating the proper atmosphere ${ }^{(* *)}$ & 3.7 & 4.7 & 2.7 & 2.1 & 1.2 & 4.1 & 4.9 & 4.8 & 5.1 \\
\hline - Creating the environment where it is easy to make suggestions & 39.2 & 38.9 & 40.0 & 50.0 & 0.0 & 50.0 & 40.0 & 42.9 & 28.6 \\
\hline - Creating a clean environment & 35.7 & 33.3 & 40.0 & 50.0 & 100.0 & 50.0 & 0.0 & 42.9 & 28.6 \\
\hline - Giving high praise for a good deed & 21.4 & 27.8 & 10.0 & 0.0 & 0.0 & 0.0 & 40.0 & 14.3 & 42.9 \\
\hline - Prohibiting the sale of goods that cause annoying behavior & 3.5 & 0.0 & 10.0 & 0.0 & 0.0 & 0.0 & 20.0 & 0.0 & 0.0 \\
\hline 3. Intervention into physical environment & 5.6 & 5.5 & 5.9 & 4.6 & 8.0 & 5.8 & 9.7 & 3.9 & 4.2 \\
\hline Improving the function and efficiency of machinery and equipment ${ }^{(* *)}$ & 5.6 & 5.5 & 5.9 & 4.6 & 8.0 & 5.8 & 9.7 & 3.9 & 4.2 \\
\hline - Improvement, installation and removal of equipment & 75.6 & 68.2 & 82.6 & 97.8 & 57.1 & 83.3 & 90.9 & 66.7 & 66.7 \\
\hline - Increasing space (Increasing the number of trains and seats) & 24.4 & 31.8 & 17.4 & 2.2 & 42.9 & 16.7 & 9.1 & 33.3 & 33.3 \\
\hline Total $(\mathrm{N})$ & 800 & 404 & 390 & 198 & 87 & 103 & 114 & 153 & 144 \\
\hline
\end{tabular}

Notes: $(*)$ Numerical values in the table indicate percentage of total

$(* *)$ Breakdown of these items is shown as percentage

$(* * *)$ For example smoking and no-smoking areas 
most desirable. Within the media categories, advertisements at stations or on trains were chosen by $43.2 \%$ and posters were chosen by $37.3 \%$, resulting in $80 \%$ of respondents when the two were combined.

The following trends were also observed.

(1) Compared with younger respondents, elderly respondents were more likely to prefer "instruction and education" and "creating the proper atmosphere". Conversely, young respondents more often preferred "establishing a penalty system".

(2) Male and younger respondents were more likely to prefer "reinforcement of patrol and surveillance" more than female and elderly respondents.

\subsection{Assessment of new policy proposals}

The results from Study 1 indicated that there were high expectations regarding the effectiveness of measures involving instruction and education. Thus, Study 2 investigated the effects of four instruction and education methods: (a) employing substantive data with figures and graphs; (b) using situations and voices of victims of annoying behavior; (c) using written descriptions explaining why a certain type of behavior can be annoying (and, in addition, describing appropriate correct behavior); (d) using humorous short poems (senryu) about manners. These proposals were evaluated with respect to five criteria; persuasive power, impact, favorable impression, attention-getting ability, and appropriateness, which were assessed on a four-point scale ( 1 = very bad, $2=$ bad, $3=$ good, 4 = excellent).

Fig. 3 showed the mean values for these five criteria. A multiple comparison (Tukey's method, $\mathrm{p}<0.05$ )) was carried out on the four criteria that were significant. The combinations with significant differences were indicated in the figure $(\mathrm{p}<0.05)$ and, as can be seen, B was selected
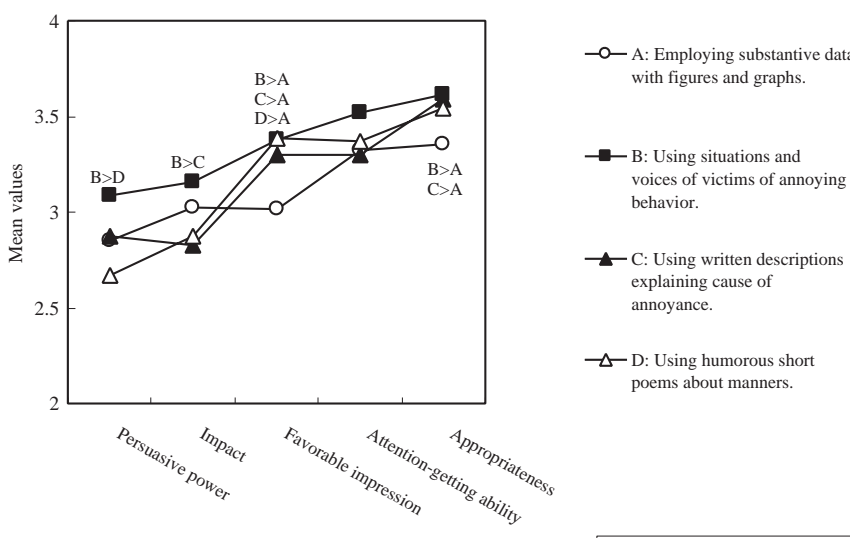

Criteri

Note : The letters indicate the results of multiple comparisons
(Tukey's method, $\mathrm{P}<0.05$ ).

Fig. 3 Patterns for choosing coping strategies and mean value of degree of discomfort

most often. Respondents choosing B made the following selections: TV commercials $(21.5 \%)$, monitors on board trains $(18.8 \%)$, posters in stations and on trains (16.5\%), public service announcements on trains (15.5\%).

\subsection{Assessment of posters displaying data}

The results of Study 1 suggested that instructional and educational public service announcements and posters could be highly effective. Thus, for the purposes of Study 2, posters were investigated to evaluate ways of making them more effective. Traditionally, instructional posters have generally employed illustrations. Therefore, trial posters using data from the current questionnaire were created and compared with traditional illustration posters. The data used on the posters was drawn from Study 1, and consisted of the seven behavior catego-

Table 5 Result of multiple comparison between three types of posters

\begin{tabular}{|c|c|c|c|c|c|c|}
\hline Annoying behavior, type of poster & & $\begin{array}{c}\text { Ease of } \\
\text { understanding }\end{array}$ & $\begin{array}{c}\text { Attention- } \\
\text { getting ability }\end{array}$ & $\begin{array}{l}\text { Favorable } \\
\text { Impression }\end{array}$ & $\begin{array}{l}\text { Persuasive } \\
\text { power }\end{array}$ & $\begin{array}{c}\text { Potential to } \\
\text { change }\end{array}$ \\
\hline Ton of vistonos & A & + & & + & + & \\
\hline 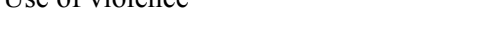 & B & + & & & & \\
\hline I ittoring & A & + & & & & \\
\hline Littinitis & B & & & - & & \\
\hline Use of collular phones on troin & A & & & - & - & \\
\hline 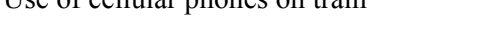 & B & & & & & + \\
\hline & A & + & & & & + \\
\hline 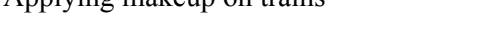 & B & + & & - & & + \\
\hline Sauntting on troinc & A & & & - & - & \\
\hline Stquating ont tiants & B & - & & - & - & \\
\hline Standing near the door, brocking board- & A & & - & - & - & \\
\hline ing / alighting passengers & B & & - & - & - & - \\
\hline ing into a troun & A & & - & - & - & \\
\hline & B & - & - & - & - & \\
\hline
\end{tabular}

Note: + sign shows significantly high difference $(\mathrm{p}<.05)$ compared with the control poster (Type A), and - sign shows significantly low difference $(\mathrm{p}<.05)$ compared with Type A poster. 
ries shown in Table 5. For each type of annoying behavior, data was displayed in two forms: Type A, using a piegraph and numeric values to show the percentage of people who find a certain type of behavior annoying; Type $\mathrm{B}$, using numeric values to show the percentage of people who find a certain type of behavior annoying based on age and gender factors (see Fig. 4). The five criteria were assessed on a four-point scale: ease of understanding, attention-getting ability, favorable impression, persuasive power, and potential to change behavior. The results of an analysis of variance (ANOVA) on the two primary factors revealed that there was a significant interaction effect among all items $(\mathrm{p}<0.05)$. Therefore, a multiple comparison (Dunnett's method) was conducted for each type of poster for a particular combination. The results summarized in Table 5 suggested that posters displaying data were given a higher rating than those promoting control of behavior with regard to violence and applying makeup on a train. These findings suggested that, when displaying surprising data, the data itself could be effective.

Besides Types A and B, another type of poster was prepared by listing in descending order the percentages of people who found particular behavior annoying (see Fig. 4). A single-factor ANOVA test was run comparing these ranking posters with the Type A posters. The results indicated that all the evaluation criteria were significant $(\mathrm{p}<0.05)$. Setting the ranking posters as control, a multiple comparison (Dunnett's method) was made. Other than "ease of understanding", the four items examined were more significant for the ranking posters than the Type A posters $(p<0.05)$. From this it could be concluded that ranking and comparative information could be expected to be more effective as an education tool.

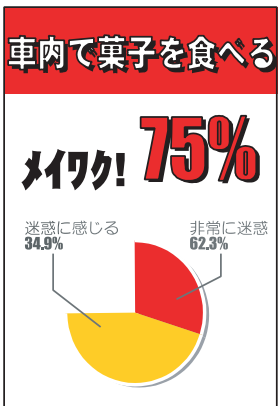

Type A

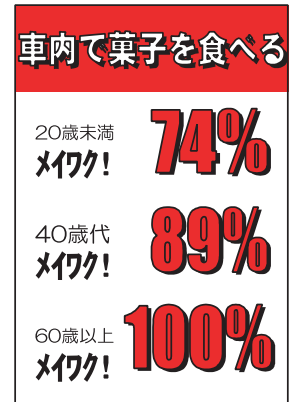

Type B

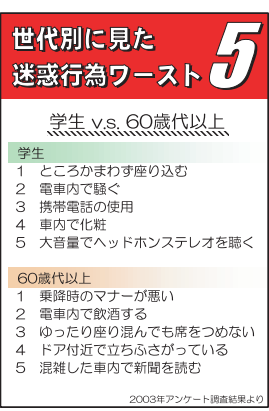

Ranking
Fig. 4 Examples of three types of posters

\section{Conclusions}

The following conclusions can be drawn from the results of this study.

(1) Passengers want railway companies to take strict countermeasures (regulative strategies) for dealing with types of behavior that have a high criminal element, involve hygiene, and other exceptionally annoying behavior that may cause serious injury. However, they prefer instructional and educational countermeasures (symbiotic strategies) for behavior that has a low level of annoyance and depends on individual common sense and those for which standards differ depending on age.

(2) Desired countermeasures differ depending on the age and gender of passengers. Older passengers were more likely to desire strategies that were based on symbiotic appeal, and younger passengers were more likely to desire those based on regulations. Furthermore, male were more likely to request patrols and surveillance than female.

(3) Among the "soft" strategies, passengers have a high degree of awareness of and desire for broadcast announcements and posters.

(4) The messages and surprise factor of posters displaying quantitative data makes them highly effective. Furthermore, ranking posters and those displaying comparative information lead to better results.

(5) The effective, vital role that broadcast media can play, such as monitors on board trains and TV commercials, has remained largely ignored until now. But this role has become apparent, depending on the broadcast content, such as for focusing on people who have been affected by annoying behavior.

Until now there have been few quantitative studies made into the strategies train companies have adopted for improving passenger manners. Therefore, the findings of the present study are significant. In this research, posters were analyzed as a "soft" strategy that can be expected to be more effectively utilized. In future studies, broadcast announcements will be similarly examined with the cooperation of railway companies' staff.

\section{References}

1) Yamauchi, K., et al., "Examining of Structures of Passengers' Morality from a Cognitive and Behavioral Perspective," RTRI Report, Vol. 18, No. 2, pp. 25-30, 2004 (in Japanese).

2) Hurst, W., Risk Assessment. The Royal Society of Chemistry, Belmont, OWF, UK, 1998 